\title{
Application of Validated Stability-Indicating HPLC Method in Stability Testing of Acetaminophen and Guaiphenesin Tablets
}

\author{
RAJYALAKSHMI CHAVAKULA ${ }^{* 1}$ and C. RAMBABU ${ }^{2}$ \\ ${ }^{* 1}$ Department of Chemistry, Vishnu Institute of Technology, Vishnupur, \\ Bhimavaram-534202, A.P, India \\ ${ }^{2}$ Department of Chemistry, Acharya Nagarjuna University, Nagarjunanagar, \\ Guntur, 522510, A.P, India \\ rajyalakshmi.ch@gmail.com
}

Received 7 August 2013 / Accepted 30 August 2013

\begin{abstract}
The aim of the work is to develop and validate the simple, fast and precise stability indicating high performance liquid chromatography method for the separation and quantification of acetaminophen and guaiphenesin in pharmaceutical dosage form. The quantification was carried out using Symmetry $\mathrm{C}_{18}(4.6 \times 150 \mathrm{~mm}, 3.5 \mu \mathrm{m})$ enhanced polar selectivity column and mobile phase comprised of potassium dihydrogen phosphate buffer $\mathrm{pH} 2.5$ and methanol in proportion of ratio $65: 35 \mathrm{v} / \mathrm{v}$. The flow rate was $\mathrm{mL} / \mathrm{min}$ and the effluent was monitored at $228 \mathrm{~nm}$. The retention time of acetaminophen and guaiphenesin were 2.6 and $4.6 \mathrm{~min}$ respectively. Linearity of acetaminophen and guaiphenesin were in the range of 50 to $90 \mu \mathrm{g} / \mathrm{mL}$ and 30 to $55 \mu \mathrm{g} / \mathrm{mL}$ respectively with correlation coefficients 0.999 . The percentage recoveries were $99.80 \%$ and $99.85 \%$ for acetaminophen and guaiphenesin respectively. There was complete separation of degradation peaks and analyte peaks, which demonstrate the specificity of assay method in the presence of its degradation products; it can be employed as a stability indicating one. Due to simplicity, rapidity and accuracy of the proposed Stability Indicating High Performance Liquid Chromatography method, it is used for analysis of stability samples of Acetaminophen and Guaiphenesin in quality control laboratories.
\end{abstract}

Keywords: Acetaminophen, Guaiphenesin, RPHPLC method, Validation, Stability studies

\section{Introduction}

Paracetamol or acetaminophen (Figure 1) chemically named as $N$-acetyl-p-aminophenol is a widely used as analgesic and antipyretic. It is commonly used for the relief of headaches and other minor aches and pains and is a major ingredient in numerous cold and flu remedies. Literature survey reveals several spectroscopic ${ }^{1-4}, \mathrm{RP}^{-H P L C} \mathrm{C}^{5-12}$ methods for the estimation of acetaminophen individually and in combination with other drugs. Guaiphenesin (Figure 2) also glyceryl guaiacolate is an expectorant drug and usually taken orally to assist the bringing up phlegm from the airways in acute respiratory tract infections. 


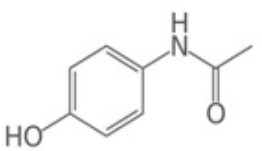

Figure 1. Acetaminophen

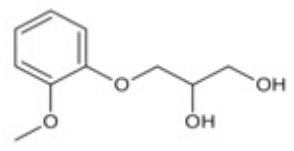

Figure 2. Guaiphenesin

The principal use of guaiphenesin is in the treatment of coughing. Chemically it is an (RS)-3-(2-methoxyphenoxy) propane-1, 2-diol. The combination of acetaminophen and guaiphenesin are used to treat headache, aches and pains, fever and chest congestion caused by common cold or flu. It also loosens phlegm (mucus) in chest to help breathe more easily. A survey of the analytical literature for guaiphenesin revealed methods based on UV spectrophotometric $^{13,14}$ and HPLC ${ }^{15-18}$ for its determination in biological fluids and in pharmaceutical formulations individually and in combination with other drugs.

In the literature few HPLC methods ${ }^{19}$ were reported for simultaneous estimation of above mentioned drugs, besides the lack of stability indication and time consuming gradient elution. The authors have developed a new, simple and fast analytical method by RP-HPLC, which is stability indicating to quantify acetaminophen and guaiphenesin in bulk and its dosage forms. It has been shown that the method presented here is rapid, convenient and sufficiently sensitive for analysis of acetaminophen and guaiphenesin in pharmaceutical dosage forms with acceptable recovery and precision. This manuscript gives the first report for the application of validated stability indicating HPLC method in stability testing of pharmaceutical dosage forms in short analysis time. The novelty of the proposed method is simple, accurate, shows good resolution with shorter run time than existing methods and applicable to stability testing of pharmaceutical dosage forms.

\section{Experimental}

Acetaminophen and guaiphenesin were obtained as gift samples from Dr. Reddy's Laboratories, Hyderabad. Sample tablets (TYLENOL ${ }^{\circledR}$ Chest Congestion) with acetaminophen $325 \mathrm{mg} \&$ guaiphenesin $200 \mathrm{mg}$ were purchased from local market. HPLC grade acetonitrile and analytical grade of potassium dihydrogen phosphate, hydrochloric acid, sodium hydroxide, hydrogen peroxide were obtained from Merck India Chemicals Ltd, Mumbai.

\section{Instrumentation and chromatographic conditions}

HPLC system (Waters 2695 LC) consisting of quaternary gradient pump, auto sampler, column oven and PDA detector (2996) was employed for analysis. The output of signal was monitored and integrated using Waters Empower software. Chromatographic analysis was performed on Symmetry Xterra $\mathrm{C}_{18}(150 \times 4.6 \mathrm{~mm}, 3.5 \mu \mathrm{m})$ column. Separation was achieved using a mobile phase consisting of phosphate buffer with $\mathrm{pH} 2.5$ and methanol in the ratio of $65: 35 \mathrm{v} / \mathrm{v}$ solutions at a flow rate of $1 \mathrm{~mL} / \mathrm{min}$ and run time was $8 \mathrm{~min}$. The column was maintained at ambient temperature and injection volume of $20 \mu \mathrm{L}$ was used. The mobile phase was filtered through $0.45 \mu$ filter prior to use. The eluent was monitored using UV detector at a wavelength $228 \mathrm{~nm}$.

\section{Preparation of standard solution}

$10 \mathrm{mg}$ of acetaminophen and $10 \mathrm{mg}$ of guaiphenesin accurately weighed and transferred into a $10 \mathrm{~mL}$ clean dry volumetric flask, about $7 \mathrm{~mL}$ of mobile phase was added and sonicated to dissolve it completely, the solution was cooled to room temperature and diluted up to volume with mobile phase and it was used as standard stock solution. $1.25 \mathrm{~mL}$ of acetaminophen and $1.0 \mathrm{~mL}$ of guaiphenesin standard stock solution was pipette out into a $10 \mathrm{~mL}$ volumetric flask and diluted up to volume with mobile phase and used as working standard solution. 


\section{Preparation of sample solution}

Finely powdered not fewer than 20 tablets of acetaminophen and guaiphenesin were weighed $10 \mathrm{mg}$ each and transferred into a $10 \mathrm{~mL}$ clean dry volumetric flask, about $7 \mathrm{~mL}$ of diluent was added and sonicated to dissolve it completely, the solution was cooled to room temperature and diluted to volume with diluent. The above sample solution was filtered through $0.45 \mu$ membrane filter. $1.25 \mathrm{~mL}$ of the above filtered sample solution was pipetted out into a $10 \mathrm{~mL}$ volumetric flask and diluted to volume with diluent.

\section{Validation of the proposed method}

The developed method was validated with respect to various parameters such as linearity, accuracy, precision and robustness, ruggedness, limit of detection and limit of quantification as per the ICH guidelines.

\section{System suitability}

The system suitability was assessed by three replicate analyses of the drugs at concentrations of $125 \mu \mathrm{g} / \mathrm{mL}$ of acetaminophen and $100 \mu \mathrm{g} / \mathrm{mL}$ of guaiphenesin. The $\%$ RSD of peak area and retention time for the both drugs are within $2 \%$ indicating the suitability of the system. Results are shown in Table 1.

Table 1. System Suitability parameters for acetaminophen and guaiphenesin by the proposed method

\section{Specificity}

\begin{tabular}{lcc}
\hline \multicolumn{1}{c}{ System suitability parameter } & Acetaminophen & Guaiphenesin \\
\hline Retention time (min) & 2.62 & 4.64 \\
Theoretical plates & 2874 & 3128 \\
Tailing factor & 1.6 & 1.2 \\
Resolution & - & 4.6 \\
\hline
\end{tabular}

The specificity of the method was performed by separate injections of the acetaminophen, guaiphenesin and the sample. The specificity chromatogram was shown in Figure 3, where the retention time of acetaminophen does not interfere with the retention time of the guaiphenesin. Also injecting diluent and placebo using the chromatographic conditions defined for the proposed method. The blank and placebo sample chromatogram showed no interference peaks at the retention time of acetaminophen and guaiphenesin respectively which demonstrates the specificity of the proposed method.

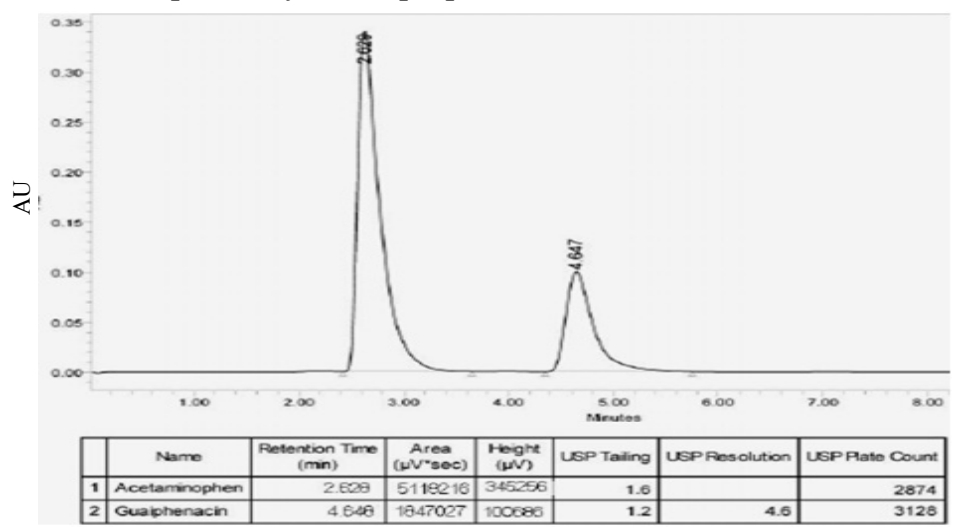

Figure 3. Typical chromatogram of acetaminophen and guaiphenesin 


\section{Linearity \& calibration curve}

Calibration curves were prepared by taking appropriate aliquots of acetaminophen and guaiphenesin standard stock solutions in different $10 \mathrm{~mL}$ volumetric flask and made up to the mark with mobile phase to obtain final concentrations of $50,60,70,80$ and $90 \mu \mathrm{g} / \mathrm{mL}$ of acetaminophen and $30,36,43,49$ and $55 \mu \mathrm{g} / \mathrm{mL}$ of guaiphenesin. Linearity curve was constructed by plotting average peak area against concentration and regression equation was computed. The statistical data calculated for acetaminophen and guaiphenesin found to be accurate and was given in Table 2 and Figure $4 \& 5$.

Table 2. Regression analysis of the calibration curves for the proposed method

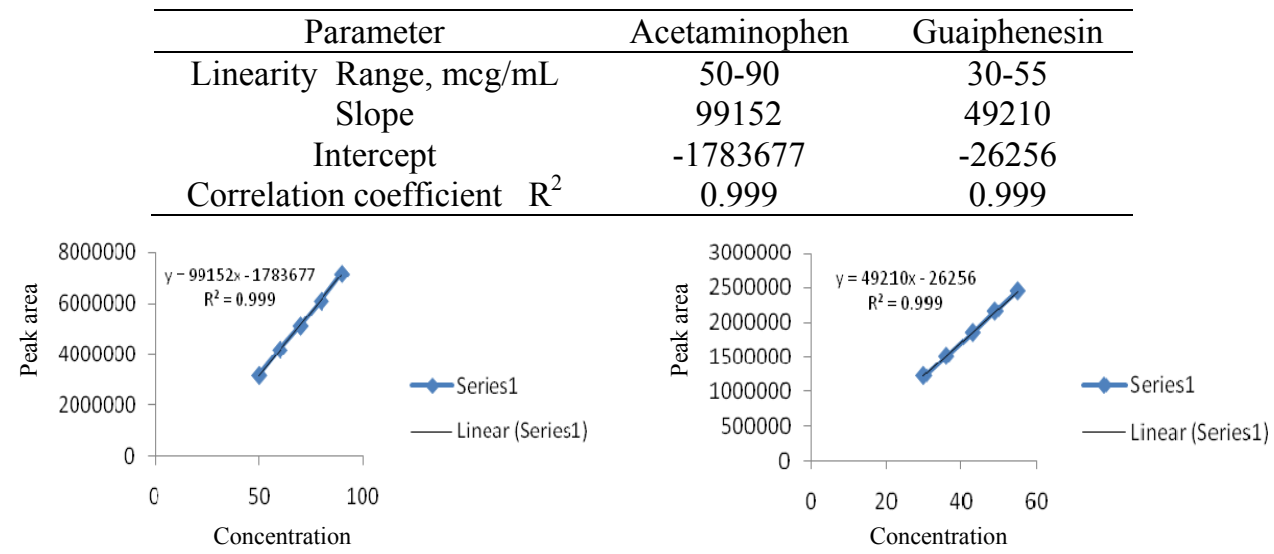

Figure 4. Linearity curve of acetaminophen

Figure 5. Linearity curve of guaifenesin

\section{Accuracy (recovery studies)}

Accuracy of the method was determined by recovery studies which were performed in triplicate by standard addition method at 50,100 and 150\%. The percentage recoveries found are in the range of 99.80 and $99.85 \%$ for acetaminophen and guaiphenesin respectively. From the data obtained, the proposed method was found to be accurate. The results are summarized in Table 3.

Table 3. Recovery data of acetaminophen and guaiphenesin

\begin{tabular}{cccccc}
\hline \% of Concentration & $\begin{array}{c}\text { Area } \\
\text { average }\end{array}$ & $\begin{array}{c}\text { Amount } \\
\text { added, mg }\end{array}$ & $\begin{array}{c}\text { Amount } \\
\text { found, mg }\end{array}$ & $\begin{array}{c}\% \\
\text { Recovery }\end{array}$ & $\begin{array}{c}\text { Mean } \\
\text { Recovery }\end{array}$ \\
\hline 50 & 2559157 & 5 & 4.99 & 99.8 & \\
100 & 5118314 & 10 & 9.98 & 99.8 & 99.80 \\
150 & 7677469 & 15 & 14.97 & 99.8 & \\
50 & 924012 & 5 & 4.99 & 99.85 & \\
100 & 1848025 & 10 & 9.99 & 99.85 & 99.85 \\
150 & 2772038 & 15 & 14.98 & 99.9 & \\
\hline
\end{tabular}

\section{Precision and intermediate precision}

The precision of the method was demonstrated by inter day and intraday variation studies. In the intraday studies, five repeated injections of sample solutions were made in a day and the 
response factor of drug peaks and percentage of RSD were calculated. In the interday variation studies, five repeated injections of sample solutions were made in different day with different make column of same dimensions. The repeatability of sample applications and measurement of peak area were expressed in terms of \%RSD and found to be less than $2 \%$ (Table 4$)$.

Table 4. Precision and intermediate precision data of acetaminophen (ACET) and guaiphenesin (GUAI)

\begin{tabular}{ccccc}
\hline & \multicolumn{2}{c}{ Intraday precision } & \multicolumn{2}{c}{ Interday precision } \\
\cline { 2 - 5 } & ACET & GUAI & ACET & GUAI \\
\hline Injection & Area & Area & Area & Area \\
\hline Injection-1 & 4684466 & 1690048 & 4934667 & 1781527 \\
Injection-2 & 4680730 & 1683628 & 4949886 & 1788651 \\
Injection-3 & 4679619 & 1690783 & 4949375 & 1790742 \\
Injection-4 & 4695633 & 1691465 & 4961354 & 1795711 \\
Injection-5 & 4687948 & 1697529 & 4973945 & 1800165 \\
Average & 4685679 & 1690691 & 4958572 & 1793267 \\
Standard & 6459.7 & 4941.1 & 17515.6 & 7873.9 \\
Deviation & & & & \\
\%RSD & 0.14 & 0.29 & 0.35 & 0.44 \\
\hline
\end{tabular}

\section{Limit of detection and limit of quantification}

The LOD is the smallest concentration of the analyte that gives a measurable response of signal to noise ratio of 3 . The LOD for acetaminophen and guaiphenesin were found to be $0.02 \& 0.05$ respectively. The LOQ is the smallest concentration of the analyte, which gives response that can be accurately quantified signal to noise ratio of 10 . The LOQ was $0.091 \&$ 0.18 of acetaminophen and guaiphenesin respectively.

\section{Robustness of method}

To evaluate the robustness of the developed RP-HPLC method, small deliberate variations in the optimized method parameters were done. The effect of change in flow rate and mobile phase ratio on the retention time and tailing factor were studied. On evaluation of the results, it can be concluded that the variation in flow rate and changes in mobile phase composition affected the method significantly. Hence it indicates that the method is robust even during change in the flow rate and mobile phase. The results are shown in Table 5.

Table 5. Robustness data of acetaminophen and guaiphenesin

\begin{tabular}{cccccc}
\hline $\begin{array}{c}\text { Sample } \\
\text { Name }\end{array}$ & Parameters & Variations & $\begin{array}{c}\text { Retention } \\
\text { time }\end{array}$ & $\begin{array}{c}\text { Tailing } \\
\text { factor }\end{array}$ & $\begin{array}{c}\text { Plate } \\
\text { count }\end{array}$ \\
\hline \multirow{4}{*}{ Acetaminophen } & Flow rate & 0.9 & 2.7 & 1.6 & 2329 \\
& Change in organic & 1.1 & 2.40 & 1.7 & 2344 \\
& composition in mobile phase & $10 \%$ less & 2.63 & 1.5 & 2426 \\
Guaiphenesin & Flow rate & 0.9 & 2.51 & 1.7 & 2271 \\
& & 1.1 & 3.6 & 1.8 & 2624 \\
& Change in organic & $10 \%$ less & 4.64 & 1.9 & 2514 \\
& composition in mobile phase & $10 \%$ more & 3.84 & 1.7 & 2633 \\
& & & & & 2508 \\
\hline
\end{tabular}




\section{Application of method to dosage form}

The proposed method was applied to the determination of acetaminophen and guaiphenesin

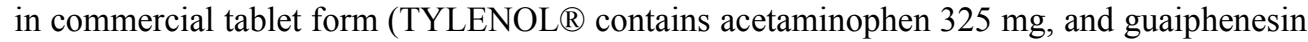
$200 \mathrm{mg}$ ). The result of these assays yielded $100 \%$ and $99.2 \%$ for acetaminophen and guaiphenesin respectively with RSD $<2 \%$. The result of the assay (Table 6) indicates that the method is selective for the assay of acetaminophen and guaiphenesin without interference from the excipients used in these tablets.

Table 6. Analysis of formulation

\begin{tabular}{cccc}
\hline Sample name & Label claim & Amount found & \% Recovery \\
\hline Acetaminophen & 325 & 325 & 100 \\
Guaiphenesin & 200 & 198.4 & 99.2 \\
\hline
\end{tabular}

\section{Stability studies}

Forced degradation studies were conducted indicating the stability of proposed method. The results of the degradation studies are presented in Table 7. The International Conference on Harmonization guideline entitled 'stability testing of new drugs and products' requires that stress testing be carried out to elucidate the inherent stability characteristics of the active substance. The aim of this work was to perform the stress degradation studies on the acetaminophen and guaiphenesin using the proposed method.

Table 7. Degradation results for acetaminophen (ACET) and guaiphenesin (GUAI)

\begin{tabular}{ccccccc}
\hline \multirow{2}{*}{ Degradation parameter } & \multicolumn{4}{c}{ Results of degradation } \\
\cline { 2 - 7 } & $\begin{array}{c}\text { Peak area of degraded } \\
\text { product }\end{array}$ & \% of recovery & \multicolumn{2}{c}{$\begin{array}{c}\text { \% of } \\
\text { Degradation }\end{array}$} \\
\cline { 2 - 7 } & ACET & GUAI & ACET & GUAI & ACET & GUAI \\
\hline $\begin{array}{c}\text { Acid Degradation } \\
(0.1 \mathrm{~N} \mathrm{HCl})\end{array}$ & 4964763 & 1774104 & 98.4 & 96.8 & 1.6 & 3.2 \\
$\begin{array}{c}\text { Base Degradation } \\
(0.1 \mathrm{~N} \mathrm{NaOH})\end{array}$ & 4862396 & 1755624 & 96.4 & 95.8 & 3.6 & 4.2 \\
$\begin{array}{c}\text { Peroxide Degradation } \\
\left(3 \% \mathrm{H}_{2} \mathrm{O}_{2}\right)\end{array}$ & 4606481 & 1663223 & 91.3 & 90.8 & 8.7 & 9.2 \\
$\begin{array}{c}\text { Thermal Degradation } \\
\left(60^{\circ} \mathrm{C}\right)\end{array}$ & 4760030 & 1700183 & 94.4 & 92.8 & 5.6 & 7.2 \\
\hline
\end{tabular}

Forced degradation studies of both the drugs were carried out under conditions of acid/base hydrolysis, oxidation and thermal hydrolysis. The drugs were subjected to acid hydrolysis by using $0.1 \mathrm{M}$ hydrochloric acid and base hydrolysis by using $0.1 \mathrm{~N}$ sodium hydroxide solution; oxidation by using 3\% hydrogen peroxide solution and thermal hydrolysis at $60{ }^{0} \mathrm{C}$. The stress conditions varied both in terms of temperature and time to achieve the appropriate degradation. All degradation studies in solution were carried out at a drug concentration at $1000 \mu \mathrm{g} / \mathrm{mL}$. The purity of the main peaks was evaluated using photodiode array detector to verify that the degradation peaks are well resolved from the main peaks. After the degradation treatments were completed, the stress content solutions were allowed to room temperature and diluted with mobile phase up to the mark. Filter the solutions with 0.45 microns filters and injected to column under proposed conditions. The forced degradation studies prove the stability indicating power of the method and can be used to assess the stability of acetaminophen and guaiphenesin in the bulk drug and in pharmaceutical dosage forms. 


\section{Results and Discussion}

The typical chromatogram of acetaminophen and guaiphenesin is shown in Figure 3, it was found that the retention times were 2.62 and $4.64 \mathrm{~min}$. which are very short retention times than earlier reported method ${ }^{19}(4.0 \& 9.5 \mathrm{~min})$. The mobile phase composition at a ratio of $65: 35(\mathrm{v} / \mathrm{v})$ of buffer $\mathrm{pH} 2.5$ and methanol was found to be most suitable to obtain peaks well defined and free from tailing. A good linear relationship ( $\mathrm{r}=0.999)$ was observed within the concentration ranges $50,60,70,80$ and $90 \mu \mathrm{g} / \mathrm{mL}$ of acetaminophen and $30,36,43,49$ and $55 \mu \mathrm{g} / \mathrm{mL}$ of guaiphenesin. Low values of S.D are indicative of high precision of the method. The assay of Tylenol tablets was found to be $100 \%$ and $99.2 \%$ for acetaminophen and guaiphenesin respectively. From the recovery studies, it was found that $99.80 \%$ of acetaminophen and $99.85 \%$ of guaiphenesin recovered which indicates high accuracy of the method. The results of LOD and LOQ indicate that the method is reliable and also shows good resolution (4.6 which is better value than earlier reported method ${ }^{19}$ value 9.2 ) with short separation time for analysis. The forced degradation studies were also carried out as per ICH guidelines. There was complete separation of degradation peaks and analyte peaks, which demonstrate the specificity of assay method for estimation of acetaminophen and guaiphenesin in the presence of its degradation products; it can be employed as a stability indicating one.

\section{Conclusion}

The proposed HPLC method is stability indicating one and less time consuming method and also satisfactory results were obtained for all validation parameters. Hence the proposed method is rapid, simple, accurate and precise. Moreover the degraded peaks were well resolved from analyte peaks. So the developed method may be used for analysis of stability samples of acetaminophen and guaiphenesin in quality control laboratories.

\section{Competing interests}

The authors declare that they have no competing interests.

\section{References}

1. $\quad$ Rashmi Agrawal, Int J Pharm Life Sci., 2013, 4(3), 2444-2446.

2. Sani Ali Audu, Alemika Emmanuel Taiwo, Bala Fatima Mohammed, Sani Musa and Ramat Bukola, Int Res J Pharm., 2012, 3(8), 165-167.

3. Patel Dasharath M, Bhavesh M Sardhara, Diglesh H Thumbadiya and Chhagan N Patel, Pharm Methods, 2012, 3(2), 98-101.

4. Khan F, Lohiya R T and Umekar M J, Int J Chem Tech Res., 2010, 2(3), 1586-1591.

5. Godse V P, Deodhar M N, Bhosale A V, Sonawane R A, Sakpal P S, Borkar D D and Bafana Y S, Asian J Res Chem., 2009, 2(1), 37-40.

6. $\quad$ Ashraful Islam S M, Int J Pharm Life Sci., 2011, 2(12), 1267-1275.

7. $\quad$ Prasanna Reddy Battu and Reddy M S, Asian J Res Chem., 2009, 2(1), 70-72.

8. $\quad$ Sharma S and Sharma M C, Int J Chem Tech Res., 2011, 3(2), 997-1002.

9. Pattan S R, Jamdar S G, Godge R K, Dighe N S, Daithankar A V, Nirmal S A and Pai M G, J Chem Pharm Res., 2009, 1(1), 329-335.

10. Sopan P. Wadhe, Dnyani P Wadhe and Bakal R L, Int J Pharm Res Develop., 2011, 3(8), 145-150.

11. Santosh N Mokale, Surekha S Nirmal, Swaroop R Lahoti and Jaiprakash N Sangshetti, Der Pharmacia Sinica, 2011, 2(5), 138-144. 
12. Veena G Kulkarni and Santosh V Gandhi, Padmanabh B Deshpande and Poonam H Chaube, Int J Pharm Pharm Sci., 2011, 3(3), 225-227.

13. Bhattacharyya I, Bhattacharyya S P, Kyal C, Choudhury P, Dhakal B and Ghosh S K, Int J Pharm Pharm Sci., 2013, 5(1), 262-268.

14. Sahu Rahul, Sharma Hemendra Kumar, Sahu Vinod, Tripathi Shruti and Jain Nilesh, Int J Res Pharm Sci., 2011, 1(3), 41-49.

15. Shruti D Deshpande, Avinash V Deosarkar and Sanjay G Walode, Der Chemica Sinica, 2012, 3(3), 759-765.

16. Andrew Asirvatham A, Manikandan K, Mailvelan R, Kishore Konam and Rajavel P, Int $J$ Biolog Pharm Res., 2012, 3(3), 463-468.

17. Sunil Pingili Reddy, Sudhakar Babu K, Navneet Kumar and Sasi Sekhar V V V, Pharm Methods, 2011, 2(4), 229-234.

18. Rahul Sahu, Sengar N P S, Parul D Mehta and NS Lodhi, Int J Pharm, 2012, 2(2), 317-321.

19. Mohammad Younus, Karunaker Reddy T, Mohiuddin and Fasiuddin Arif, Int J Pharm Pharm Sci., 2012, 4(1), 623-626. 